\title{
USING AIR QUALITY MODELLING AND EMISSION PROJECTIONS AS A SUPPORT TO THE FIRST AIR POLLUTION CONTROL PROGRAM UNDER NEC DIRECTIVE TARGETS FOR 2030
}

\author{
JOANA FERREIRA ${ }^{1}$, DIOGO LOPES ${ }^{1}$, SÍLVIA COELHO ${ }^{1}$, ALEXANDRA MONTEIRO $^{1}$, MYRIAM LOPES ${ }^{1}$, \\ DÍLIA JARDIM ${ }^{2}$, FILIPA MARQUES ${ }^{2}$, FILOMENA BOAVIDA ${ }^{2} \&$ ANA I. MIRANDA ${ }^{1}$ \\ ${ }^{1}$ Department of Environment and Planning \& CESAM, University of Aveiro, Portugal \\ ${ }^{2}$ Portuguese Environment Agency, Portugal
}

\begin{abstract}
The new National Emission Ceilings (NEC) Directive was transposed into Portuguese law in 2018 creating the obligation to comply with the established NEC for Portugal and to develop a National Air Pollution Control Programme (NAPCP). An analysis of emission trends and projections, and potential air quality and environmental impacts, was performed as a support to the NAPCP. Notwithstanding the emissions reduction trend, NEC noncompliance cases are still foreseen for SOx, NMVOC and $\mathrm{PM}_{2.5}$ under a 2030 current level legislation scenario. In terms of air quality impacts, a likely compliance with air quality objectives for health protection is expected for $\mathrm{NO}_{2}$ and $\mathrm{PM}_{2.5}$, with an increase of $\mathrm{O}_{3}$ levels. Based on the obtained results, it is possible to identify the need for further emission reduction measures and for the air quality simulation of other scenarios.
\end{abstract}

Keywords: NEC directive, emission projections, air quality impacts, modelling.

\section{INTRODUCTION}

The latest report by the European Environment Agency raises awareness for the high population in Europe still exposed to dangerous levels of atmospheric pollution that can lead to premature mortalities. Beyond the impact on human health, air pollutants also have adverse effects on the environment, namely causing crop losses and acidification of soils and surface waters [1]. To ensure the reduction of these negative impacts, the revised directive on National Emissions Ceilings (NEC), published in 2016, sets stricter targets, expressed as a percentage reduction of 2005 emissions, for the air pollutants included in the previous regulation $\left(\mathrm{SO}_{2}, \mathrm{NO}_{\mathrm{X}}, \mathrm{NMVOC}\right.$ and $\left.\mathrm{NH}_{3}\right)$, and an additional ceiling for $\mathrm{PM}_{2.5}$ [2]. The new reduction commitments for 2030 are designed to implement the reduction of air quality impacts by 2030 established in the Communication on a Clean Air Programme for Europe [3]. Compliance with these commitments is also expected to contribute to the European Union's long-term objective of achieving levels of air quality in line with the guidelines of the World Health Organization. Full compliance with European air quality standards can be achieved in the short to medium term by focusing on the implementation of existing policy plus Member State action, and thus substantially tighter emission reduction commitments are needed.

The NEC Directive fine tunes the provisions and requires each Member State to draw-up, adopt and to regularly update a national air pollution control programme (NAPCP), taking into account the wider air quality challenges of the Member State with a view to ensuring that the 2020, 2025 and potentially also the 2030 NECs are met in time, contributing effectively to the achievement of the European air quality objectives and without significantly impacting air quality in neighbouring Member States.

The background information and the policies and measures selected for implementation, to be included in the NAPCP, shall not only be determined through the evaluation of the 
extent of the emission reductions to be achieved, but also on the obligation to prevent or reduce the transboundary air pollution impact, to contribute to the achievement of European air quality objectives and to ensure coherence with any other relevant national plans or programmes. To this effect, Member States should take into account the need to reduce emissions in zones and agglomerations affected by excessive air pollutant concentrations and/or in those that contribute significantly to air pollution in other zones and agglomerations. NAPCPs should, therefore, contribute to the successful implementation of air quality plans enacted under the European Air Quality Directive.

Portugal is still facing atmospheric pollution problems, especially in urban areas, and had to develop and implement air quality plans to further reduce emissions aiming to improve air quality [4]-[7]. In this sense, it is important to assess and control national emissions, considering their spatial variability, in an integrated way, with the future perspective, to comply with the new NEC Directive commitments and, at the same time, fulfil the air quality objectives/standards.

To support the NAPCP development for Portugal, an analysis of emission trends and projections, and an evaluation of impacts on air quality and on the environment should be performed. In this context, this work aims to present the outcomes of the ongoing project FUTURAR - Air quality in Portugal in 2030 - a policy support (http://futurar.web.ua.pt/en/project), in what concerns the:

1. Analysis of the national emission projections submitted under the Convention on Longrange Transboundary Air Pollution (LRTAP), against the NEC established for Portugal;

2. Assessment of the impacts on air quality and ecosystems of these projections;

3. Evaluation of potential NEC and EU air quality targets compliance, and identification of possible non-compliant areas in the country.

\section{METHODOLOGY}

This study focuses on the evaluation of emission projections and their impacts on air quality and environment under the NEC Directive. Firstly, an analysis of emission trends and latest submitted projections for 2020, 2025 and 2030 was carried out aiming to verify the compliance of NEC considering the current legislation until 2030 (CLE scenario, without additional measures). Then, an estimation of air quality impacts and an evaluation of the legislation fulfilment were performed.

The Air Quality Directive defines annual limit values of 40 and $25 \mu \mathrm{g} \cdot \mathrm{m}^{-3}$ for $\mathrm{NO}_{2}$ and $\mathrm{PM}_{2.5}$ concentrations respectively, and establishes a maximum daily 8-hour mean of 120 $\mu \mathrm{g} . \mathrm{m}^{-3}$ for $\mathrm{O}_{3}$, that could not be exceeded in more than 25 days per year. To evaluate the air pollution impacts and identify potential areas of non-compliance of the air quality targets defined in the EU Air Quality Directive (2008/50/EC), the air quality modelling system WRF-CAMx was applied over Portugal with a spatial resolution of $0.05^{\circ}$, driven by a coarser domain over Europe at $0.25^{\circ}$ by a two-way nesting approach.

The air quality modelling system includes the Weather Research \& Forecasting (WRF) (Version 3.7.1) model [8], and the Comprehensive Air Quality Model with Extensions (CAMx) (Version 6.4) [9]. Two simulations were performed: base case (as reference) and future scenario. The reference scenario considered the latest gridded emissions available (EMEP 2015) [10], disaggregated by sector and pollutant, for the simulation domain resolution of $0.05^{\circ}$. For the future scenario, the 2030 national projections were disaggregated assuming the same spatial distribution of emissions by activity sector and pollutant. All other 
input data (meteorology, initial and boundary conditions of the European domain) were kept the same in both simulations.

To assess the impacts of air pollutants on vegetation and natural ecosystems, the Air Quality Directive defines critical levels (for $\mathrm{SO}_{2}$ and $\mathrm{NO}_{\mathrm{X}}$ ) and the Accumulated Ozone exposure over a Threshold of $40 \mathrm{ppb}\left(=80 \mu \mathrm{g} \cdot \mathrm{m}^{-3}\right)$ (AOT40). The long-term critical level for $\mathrm{SO}_{2}$ is $20 \mu \mathrm{g} \cdot \mathrm{m}^{-3}$ as an annual mean and this value is applied during the winter period (from 1 October to 31 March). While for the $\mathrm{NO}_{\mathrm{X}}$, the annual air quality guideline is $30 \mu \mathrm{g} \cdot \mathrm{m}^{-3}$. Regarding the AOT40, this parameter is the sum of the difference between hourly concentrations greater than $80 \mu \mathrm{g} . \mathrm{m}^{-3}$ during the summer period (May to July) using only the one-hour values between $8 \mathrm{am}$ and $8 \mathrm{pm}$ of each day. This indicator is designed for the protection of crops and forests and the target value is $18000\left(\left(\mu \mathrm{g} \cdot \mathrm{m}^{-3}\right) \cdot \mathrm{h}\right)$.

In this work, the critical levels and AOT40 were estimated for the outputs from the air quality modelling system and using the Portuguese land use dataset at high spatial resolution [11], to provide the air pollution risks only on the grid cells with more than $50 \%$ of vegetation.

\section{EMISSION TRENDS AND PROJECTIONS}

Under the United Nations Economic Commission for Europe (UNECE) Convention on Long-Range Transboundary Air Pollution of 1979 (CLRTAP) and related Protocols, Member States report annual emission inventory information from 1990 until the current year minus 2 years. Ferreira et al. [12] analysed the evolution of the Portuguese national emissions and the compliance of old NEC Directive in 2010. The emission inventories reported to the EC show that emissions in Portugal presented a consistent decreasing trend for all pollutants until 2014, and slight decreases and increases from 2015 onwards. The 2010 targets were achieved with measures implemented at the time, which allowed Portugal to even surpass the defined goals.

As an additional requirement, emission projections for $\mathrm{SO}_{2}, \mathrm{NO}_{\mathrm{X}}, \mathrm{NH}_{3}, \mathrm{NMVOCs}, \mathrm{PM}$ and, if available, black carbon (BC) must be reported. The projections shall cover the years 2020, 2025, 2030 and, where available, 2040 and 2050. Projected emissions are used to assess whether or not Member States are on track towards meeting their reduction commitments for 2020 and 2030 [13].

Considering that NEC targets are based on emission reduction percentages of the 2005 emissions and based on the latest projections reported by Portugal, Fig. 1 presents the national emissions for 2005 and 2015 (considered as the reference year for the present study) and the Portuguese projections for 2030, by activity sector.

Comparing 2005 and 2015 emissions, it can be concluded that Portugal is performing well in reducing its atmospheric emissions. However, efforts are still required to further reduce the 2015 levels. The analysis of emission projections indicates that national commitments based on current legislation are not enough to achieve NEC in 2030 and additional measures are needed, namely, to control SOx, NMVOC and $\mathrm{PM}_{2.5}$ emissions. Moreover, actions are mainly required for the industrial sector as the main contributor to the referred pollutants.

\section{AIR QUALITY AND ENVIRONMENTAL IMPACTS}

\subsection{Air quality impacts}

The outputs of the WRF-CAMx system for 2015 and 2030 were processed to get annual averages and differences between the reference and the future scenario over the study region as represented in Fig. 2. 


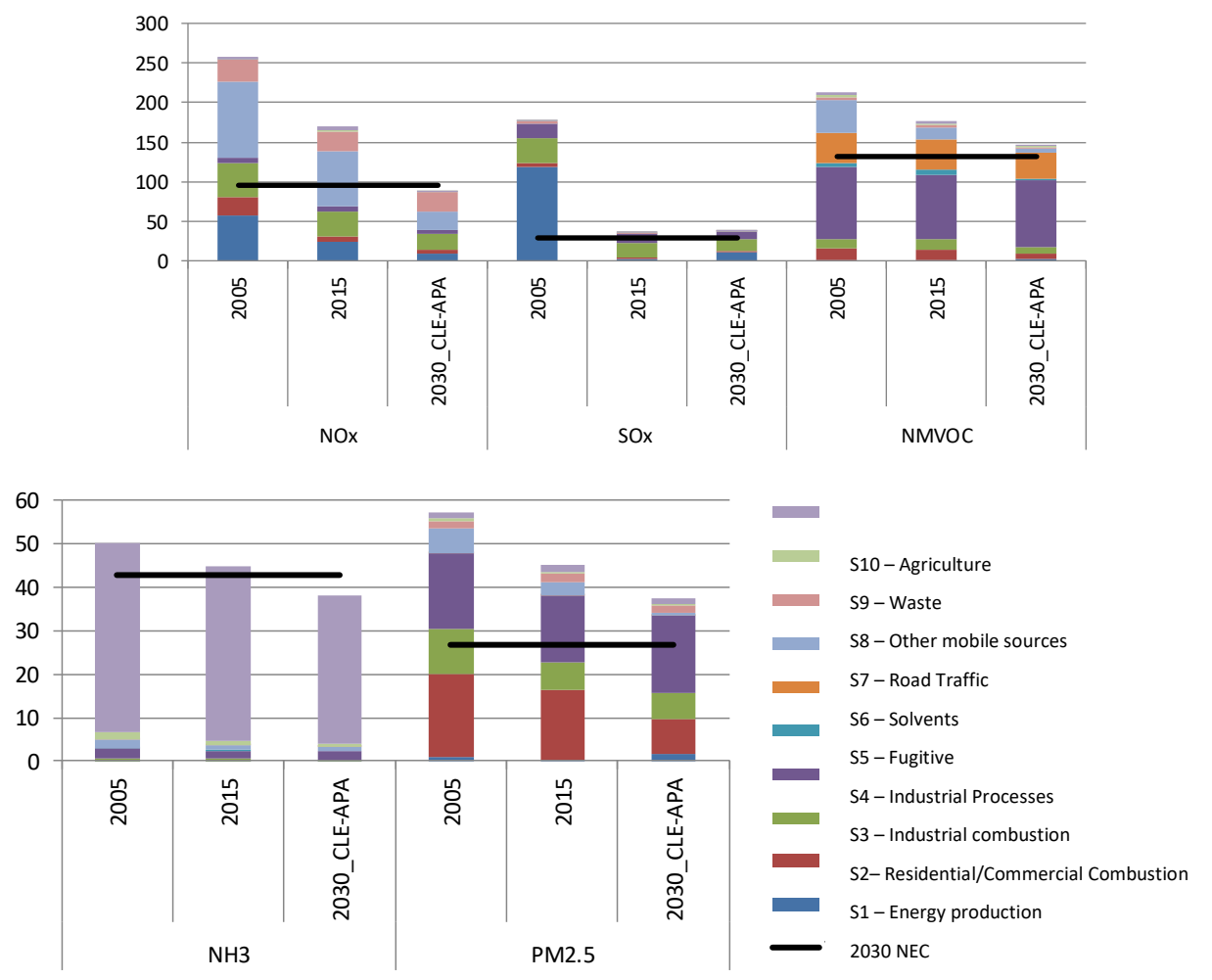

Figure 1: National emissions (in kton) by SNAP activity sector for 2005 and 2015 (reported in 2017) and emission projections reported in 2017 for CLE scenario by the Portuguese Environment Agency.

According to the air quality results, a decrease of $\mathrm{NO}_{2}$ annual average concentrations is expected for 2030 mainly in the urban areas of Porto and Lisbon, with a maximum decrease of $15 \mu \mathrm{g} . \mathrm{m}^{-3}$. Regarding $\mathrm{PM}_{2.5}$, the model simulates increases and decreases for the annual average. A maximum decrease of $10 \mu \mathrm{g} . \mathrm{m}^{-3}$ was obtained and increases up to $15 \mu \mathrm{g} . \mathrm{m}^{-3}$ were achieved in particular areas, where large industrial point sources are located. For $\mathrm{O}_{3}$, the results indicate averaged increases of 5 to $20 \mu \mathrm{g} . \mathrm{m}^{-3}$.

To evaluate the potential compliance of the air quality objectives in 2030 based on the national emission projections, the legislated parameters were computed for the future scenario air quality results: $\mathrm{NO}_{2}$ and $\mathrm{PM}_{2.5}$ annual average concentrations and the number of exceedances of the $\mathrm{O}_{3}$ target value. The maps presented in Fig. 3 exhibit the likely, uncertain and unlikely compliance of the objectives based on the targets set by the Air Quality Directive.

Compared to a reference scenario based on 2015 emissions spatial distribution in Portugal, the impacts of CLE projections for 2030 considering the same share in the spatial distribution of emissions by pollutant and sector reveal a likely compliance of air quality objectives for $\mathrm{NO}_{2}$ and $\mathrm{PM}_{2.5}$ objectives in the whole country - Continental Portugal. For $\mathrm{O}_{3}$, the estimated impact indicates a higher area with non-compliance in 2030. This can be justified by the fact 

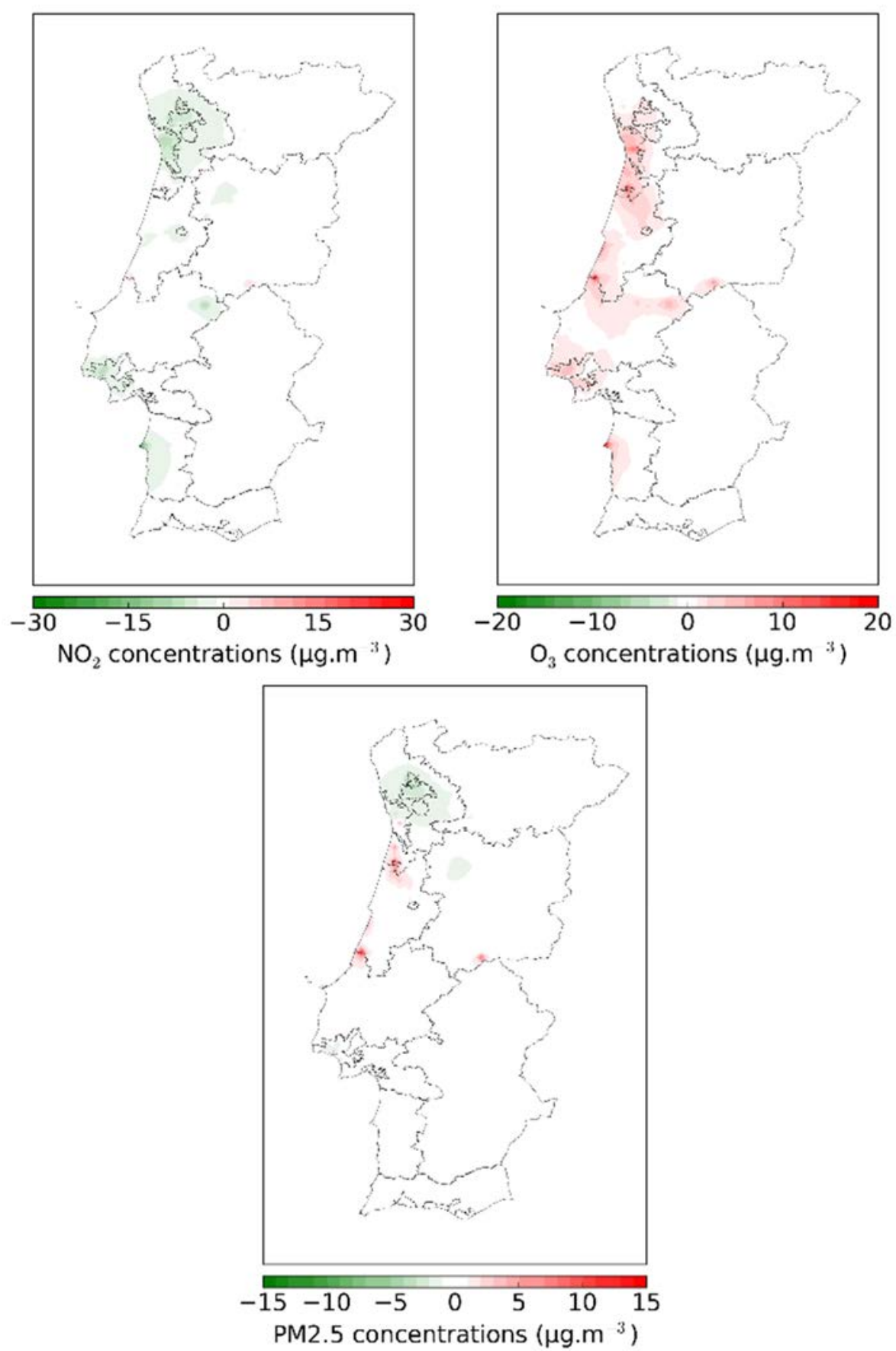

Figure 2: Differences between the annual average concentrations modelled by WRFCAMx for reference and the future scenario, for $\mathrm{NO}_{2}, \mathrm{O}_{3}$ and $\mathrm{PM}_{2.5}$ pollutants. 


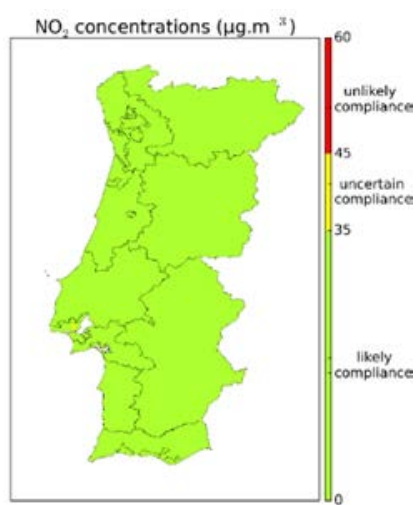

(a)

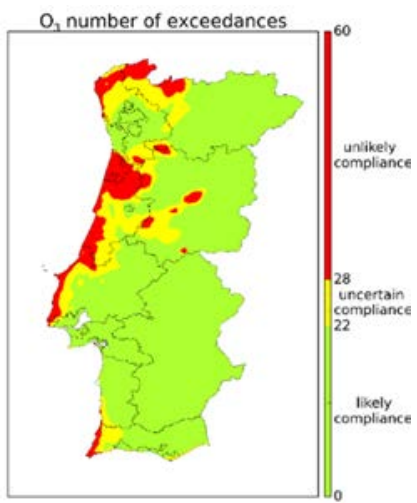

(b)

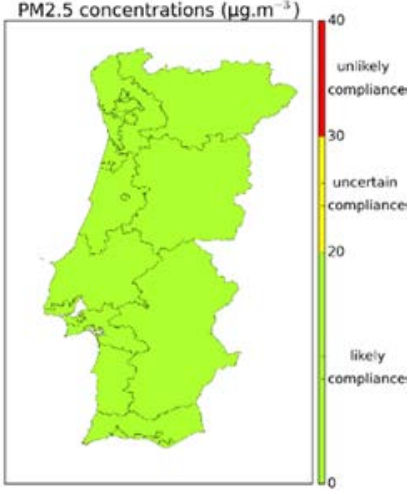

(c)

Figure 3: Compliance of air quality objectives based on Portuguese emission projections for 2030. (a) $\mathrm{NO}_{2}$ annual limit value; (b) Maximum number of exceedances of $\mathrm{O}_{3}$ target value; (c) $\mathrm{PM}_{2.5}$ annual limit value.

that projected emissions estimate a decrease of $\mathrm{NO}_{\mathrm{X}}$ emissions and an increase on NMVOC emissions, which is particularly reflected in rural areas. A further investigation on the $\mathrm{NO}_{\mathrm{X}} /$ VOC ratio regimes is required to better understand the obtained results.

\subsection{Environmental impacts}

The vegetation and ecosystem potential impacts of emission projections for 2030 were estimated by the calculation of critical levels (for $\mathrm{SO}_{2}$ and $\mathrm{NO}_{\mathrm{X}}$ ) and AOT40. Figs. 4 and 5 display the AOT40 and $\mathrm{SO}_{2}$ and $\mathrm{NO}_{\mathrm{X}}$ obtained results, respectively, for crop and forest areas in the country according to the Portuguese land use database.
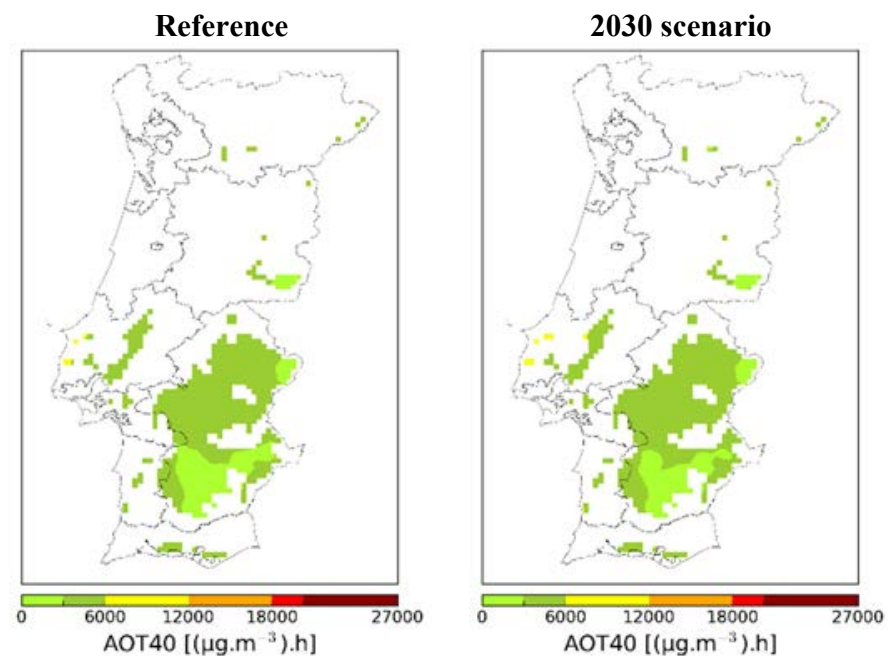

Figure 4: AOT40 levels in crop and forested areas obtained for the reference case and 2030 scenario based on $\mathrm{O}_{3}$ modelled concentrations. 

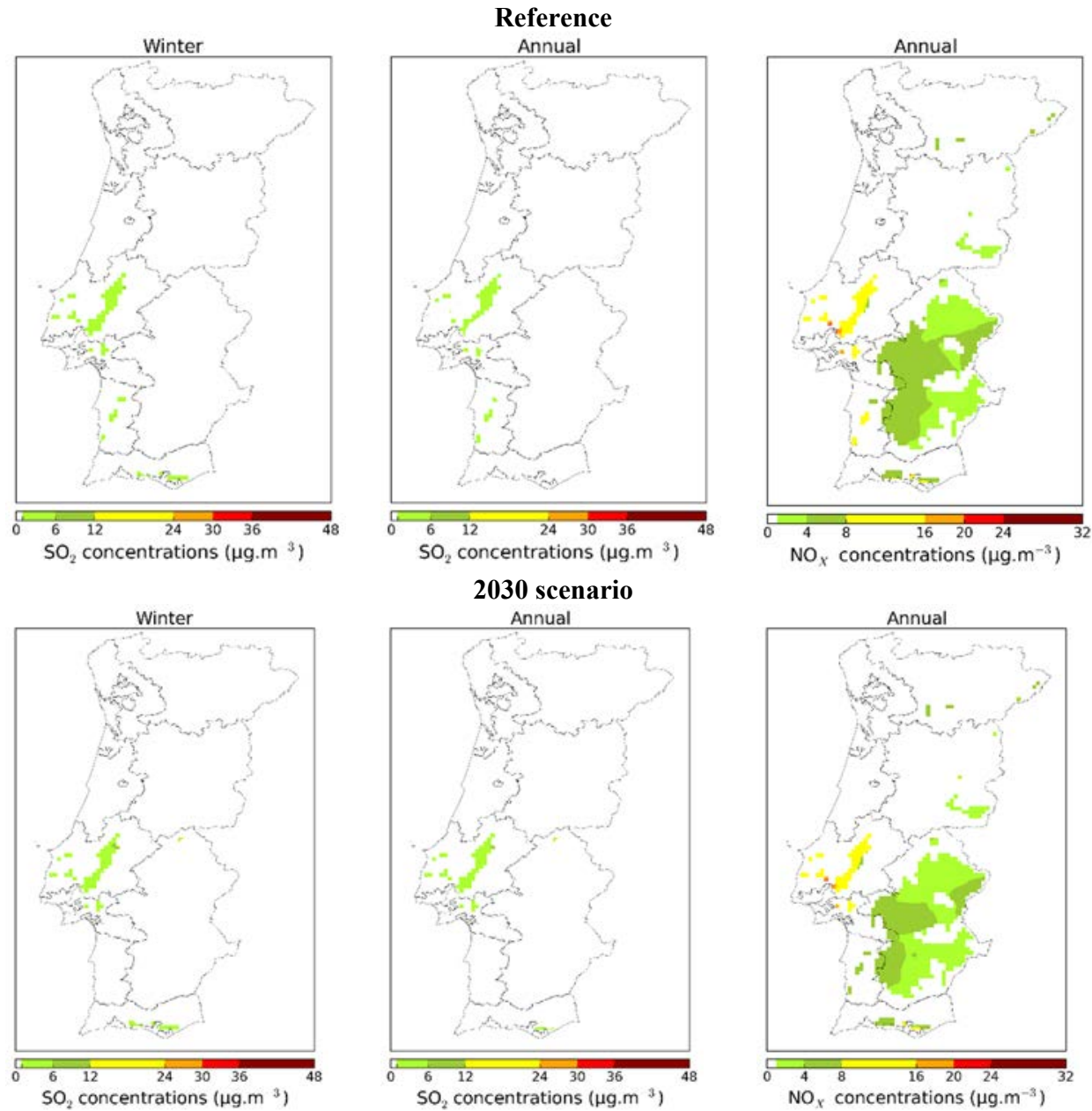

Figure 5: Critical levels for $\mathrm{SO}_{2}$ and $\mathrm{NO}_{\mathrm{X}}$ obtained for the reference and the future scenarios based on modelled concentrations.

AOT40 ozone values are below the limit value, and with similar patterns and levels, for both reference and future scenarios, indicating a likely compliance of the legislation (Fig. 4). Concerning the estimated $\mathrm{SO}_{2}$ critical levels, both for winter and entire year, values are below the legal target for the reference case, and even a slight decrease is expected in the future, especially in the south of the country. For $\mathrm{NO}_{\mathrm{X}}$, critical levels calculated for reference and future scenarios reveal an uncertain compliance of the target value in the agricultural area northeast of Lisbon, along the Tagus river basin.

\section{FINAL REMARKS}

In this work an analysis of atmospheric emission trends and projections was performed in the scope of the National Emission Ceilings Directive that should be accomplished from 2030 onwards, aiming to achieve the established ceilings in 2030. Moreover, as a support to the development of the National Air Pollution Control Program (NAPCP), required by the NEC 
Directive, the WRF-CAMx air quality modelling system was used to evaluate the impacts of emission projections on air quality and environment.

The emission projections considering the current legislation until 2030 reveal that additional measures for further emission reductions are required to attain the NEC targets established for Portugal. Notwithstanding, in terms of air quality impacts, a likely compliance with air quality objectives for health protection is expected for $\mathrm{NO}_{2}$ and $\mathrm{PM}_{2.5}$. However, a degradation of air quality regarding $\mathrm{O}_{3}$ is potentially foreseen. Regarding impacts on vegetation and ecosystems, there are no special concerns, except for $\mathrm{NO}_{\mathrm{X}}$ critical levels, although modelling results show a tendency of reducing risk in the future.

It must be highlighted that, in this study, land use change was not considered for the 2030 simulation nor the climate forcing, since the objective was to evaluate the impacts of future emissions.

Future work will include the design and assessment of the most efficient emission reduction measures to comply with the NEC and minimize impacts on air quality, environment and health.

\section{ACKNOWLEDGEMENTS}

This work was supported by the project FUTURAR (PTDC/AAG-MAA/2569/2014-POCI01-0145-FEDER-016752) funded by FEDER, through COMPETE2020 - Programa Operacional Competitividade e Internacionalização (POCI), and by national funds (OE), through FCT/MCTES. J. Ferreira is funded by national funds (OE), through FCT Foundation for Science and Technology, I.P., in the scope of the framework contract foreseen in the numbers 4, 5 and 6 of the article 23, of the Decree-Law 57/2016, of August 29, changed by Law 57/2017, of July 19 . Thanks are also due for the financial support to the $\mathrm{PhD}$ grant of S. Coelho (SFRH/BD/137999/2018), and to CESAM (UID/AMB/50017/2019), to FCT/MCTES through national funds, and the co-funding by the FEDER, within the PT2020 Partnership Agreement and Compete 2020.

\section{REFERENCES}

[1] EEA (European Environment Agency), Air quality in Europe - 2018 report. EEA Report No 12/2018. Luxembourg: Publications Office of the European Union. ISBN 978-92-9213-989-6, 2018.

[2] EU, Directive (EU) 2016/2284 of the European Parliament and of the Council of 14 December 2016 on the reduction of national emissions of certain atmospheric pollutants, amending Directive 2003/35/EC and repealing Directive 2001/81/EC, 2016.

[3] EC, Communication from the Commission to the European Parliament, the Council, the European Economic and Social Committee and the Committee of the Regions. A Clean Air Programme for Europe. COM(2013) 918 final, 2013.

[4] Borrego, C. et al., Air quality plan for ozone: a case-study in North Portugal. Air Quality Atmosphere \& Health, 9(5), pp. 447-460, 2016.

[5] Borrego, C., Monteiro, A., Sá, E., Carvalho, A., Coelho, D., Dias, D. \& Miranda, A. I., Reducing $\mathrm{NO}_{2}$ pollution over urban areas: air quality modelling as a fundamental management tool. Water, Air, Soil \& Pollution, 223(8), 5307-5320. 2012.

[6] Duque, L. et al., Evaluating strategies to reduce urban air pollution. Atmospheric Environment, 127, 196-204, 2016.

[7] Monteiro, A. et al., Air quality over Portugal in 2020. Atmospheric Pollution Research, 6(5), pp. 788-796, 2015. 
[8] Skamarock, W. C. et al., A Description of the Advanced Research WRF Version 3. NCAR/TN-475+STR Ncar Technical Note. 2008

[9] ENVIRON, CAMx. User's Guide. Comprehensive air quality model with extensions. Vrs. 6.4. 2016.

[10] APA, Portuguese informative inventory report 1990-2015 submitted under the NEC Directive (EU) 2016/2284 and the UNECE convention on long-range transboundary air pollution". Portuguese Environmental Agency. 2017.

[11] DGT, (Direção Geral do Território), 2018. Cartografia de Uso e Ocupação do Solo (COS, CLC e Copernicus). Online. www.dgterritorio.pt. Accessed on: 19 Oct. 2018.

[12] Ferreira, J., Leitão, J., Monteiro, A., Lopes, M. \& Miranda, A.I., National Emission Ceilings in Portugal - Trends, compliance and projections. Air Quality Atmosphere Health, 10(9), pp. 1089-1096. 2017.

[13] EEA (European Environment Agency), National Emission Ceilings (NEC) Directive reporting status 2018. Briefing no. 6/2018. www.eea.europa.eu/themes/air/nationalemission-ceilings/nec-directive-reporting-status-2018. Accessed on: 23 Apr. 2019 